\title{
Laparoscopy-assisted Distal Gastrectomy for Gastric Cancer in Elderly Patients: Surgical Outcomes and Prognosis
}

\author{
KENICHI ARATANI ${ }^{1}$, SHINICHI SAKURAMOTO ${ }^{1}$, MOTOHIRO CHUMAN ${ }^{1}$, MASATO KASUYA $^{1}$, \\ MITSUO WAKATA ${ }^{1}$, YUTAKA MIYAWAKI ${ }^{1}$, HISASHI GUNJI ${ }^{1}$, HIROSHI SATO ${ }^{1}$, \\ KOJUN OKAMOTO $^{1}$, SHIGEKI YAMAGUCHI ${ }^{1}$, EIGO OTSUJI ${ }^{2}$ and ISAMU KOYAMA ${ }^{1}$ \\ ${ }^{1}$ Division of Digestive Surgery, Department of Surgery, \\ International Medical Center, Saitama Medical University, Hidaka, Japan; \\ ${ }^{2}$ Division of Digestive Surgery, Department of Surgery, Kyoto Prefectural University of Medicine, Kyoto, Japan
}

\begin{abstract}
Background/Aim: Elderly patients usually have various comorbidities. Laparoscopic gastrectomy as a minimally-invasive treatment might be feasible for these patients. The aim of this study was to evaluate the safety and efficacy of laparoscopy-assisted distal gastrectomy (LADG) in elderly patients with gastric cancer by comparing the surgical outcomes and prognosis. Patients and Methods: We analyzed 136 patients who had undergone LADG between January 2013 and December 2014. We compared elderly patients (75 years old or more) with non-elderly patients. Results: The incidence of all postoperative complications did not differ between groups, and there were no significant differences in the time to first oral intake or the duration of postoperative hospital stay. The 3-year overall and recurrence-free survival rates were not significantly different between the groups. Conclusion: LADG is a safe and less invasive treatment for gastric cancer in elderly patients, who have a greater incidence of comorbidity.
\end{abstract}

Gastric cancer is the fifth most common and the third leading cause of cancer-related death from malignancies worldwide, with an especially high incidence in East Asian countries (1). The average age of the population and consequently the number of elderly people has been increasing all over the world (2). The number of Japanese people aged 65 years or older has nearly quadrupled in the past 40 years to comprise $27 \%$ of the total population in 2016 (Statistics Bureau,

Correspondence to: Kenichi Aratani, MD, Division of Digestive Surgery, Department of Surgery, International Medical Center, Saitama Medical University, 1397-1 Yamane, Hidaka City, Saitama 350-1298, Japan. Tel: +81 429844111, Fax: +81 429844741, e-mail: aratani@koto.kpu-m.ac.jp

Key Words: Gastric cancer, elderly patients, laparoscopic gastrectomy, prognosis. http://www.stat.go.jp/english/data/jinsui/tsuki/index.htm), making Japan the country with the highest proportion of elderly people in the world. Therefore, the incidence of gastric cancer among the elderly has increased, and it is expected that a larger number of these elderly patients will be candidates for gastric resection (3). However, elderly patients generally have decreased physical function, various comorbidities and the potential risk of postoperative complications $(4,5)$.

Recently, several studies have suggested that laparoscopic or laparoscopy-assisted gastrectomy is more suitable for elderly patients with early gastric cancer than conventional open gastrectomy because of its minimal invasiveness $(6,7)$. In addition, laparoscopic gastrectomy has shown acceptable surgical outcomes in such patients, comparable to those in non-elderly patients (8-11). However, most of the studies focused only on surgical outcome, and very few on the prognosis of elderly patients with gastric cancer who underwent laparoscopic gastrectomy.

In this study, we evaluated the surgical short-term outcome of laparoscopy-assisted distal gastrectomy (LADG) in patients with gastric cancer aged 75 years and over and in non-elderly patients, and analyzed the prognosis of these two groups.

\section{Patients and Methods}

Patients. This study evaluated 136 patients who had undergone LADG including regional lymph node dissection for gastric cancer between January 2013 and December 2014 at our Institute. All patients were diagnosed according to the Japanese Classification of Gastric Carcinoma by the Japanese Gastric Cancer Association (12). No patients in the present study had received neo-adjuvant chemotherapy. As an objective evaluation of patient status, the American Society of Anesthesiologists (ASA) score was examined (13). The median length of follow-up for censored cases was 37 months (range=6-56 months). All patients were informed of this study, and written informed consent was obtained. The present study was approved by the Institutional Review Board of our hospital (No.17-192). We divided the patients into two groups: elderly (aged $\geq 75$ years, 36 patients) and non-elderly 
(aged $<74$ years, 100 patients). The clinicopathological characteristics, short-term surgical outcomes and 3-year prognosis were compared between the two groups.

Operative techniques. Standard operability for each case was decided according to the Japanese Gastric Cancer Treatment Guidelines (14). For both groups, surgery was performed by the same procedure. A $12-\mathrm{mm}$ camera port was inserted below the umbilicus by the open technique, and pneumoperitoneum was induced with carbon dioxide up to a pressure of $10 \mathrm{mmHg}$ then the other four ports were inserted. After resection of the stomach, a 7-cm incision was made in the midline of the upper abdomen. For anastomosis, Billroth type I reconstruction was performed directly through the small incision. When the gastric remnant was small or tension was noted at the anastomosis in obese patients, the Roux-en-Y or Billroth type II method was used (15).

Statistical analysis. Clinicopathological variables pertaining to the corresponding patients were analyzed for statistical significance using the chi-squared test or Fisher's exact test. For the analysis of survival, Kaplan-Meier survival curves were constructed for groups based on univariate predictors, and differences between the groups were analyzed with the log-rank test. Differences were assessed with a twosided test and were considered statistically significant at $p<0.05$.

\section{Results}

Patient characteristics. The clinicopathological characteristics of all 136 patients are shown in Table I. The mean age of the elderly group was $79.3 \pm 3.3$ years, with 27 men and nine women. The mean body-mass-index (BMI) was $23.2 \pm 2.4$ $\mathrm{kg} / \mathrm{m}^{2}$. The elderly group had significantly higher ASA scores (ASA $\geq 3,22 \%$ vs. 7\%, $p=0.0252$ ) and lower preoperative hemoglobin and albumin than the non-elderly group, whereas sex, BMI, tumor size and histological type of tumor were similar in the two groups. A total of 21 patients (58\%) had stage I, seven (19\%) had stage II, and eight (22\%) had stage III tumors in the elderly group, and there were no significant differences in the pathological stages between the two groups.

Short-term surgical outcomes. In the elderly group, 12 patients (33\%) underwent D2 lymph node dissection. The mean operative time was $296.5 \pm 63.0$ minutes, and the mean intraoperative blood loss was $66.4 \pm 84.6 \mathrm{ml}$. Compared to the non-elderly group, there were no significant differences in the reconstruction methods, operative time, operative blood loss and the level of lymph node dissection, whereas the number of harvested lymph nodes was smaller in the elderly group (Table II). The time to first oral intake after surgery and the duration of postoperative hospital stay were similar for both groups. After surgery, there were no significant differences in overall complications between the elderly (28\%) and non-elderly $(15 \%)$ groups $(p=0.1301)$. Moreover, there were also no significant differences in the severity of complications of Clavien-Dindo grade IIIa and above between the two groups (11\% vs. 5\%, $p=0.2442)$. In this study, no patient died after
Table I. Patient characteristics.

\begin{tabular}{|c|c|c|c|}
\hline & \multicolumn{2}{|c|}{ LADG group $(n=136)$} & \multirow[b]{2}{*}{$p$-Value* } \\
\hline & $\begin{array}{l}\text { Elderly } \\
(\mathrm{n}=36)\end{array}$ & $\begin{array}{l}\text { Non-elderly } \\
\quad(\mathrm{n}=100)\end{array}$ & \\
\hline Age (years) $)^{\mathrm{a}}$ & $79.3(3.3)$ & $63.3(8.8)$ & $<0.0001$ \\
\hline Gender, n (\%) & & & 0.8289 \\
\hline Male & $27(75)$ & $72(72)$ & \\
\hline Female & $9(25)$ & $28(28)$ & \\
\hline BMI $\left(\mathrm{kg} / \mathrm{m}^{2}\right)^{\mathrm{a}}$ & $23.2(2.4)$ & $22.6(3.0)$ & 0.3110 \\
\hline Hemoglobin $(\mathrm{g} / \mathrm{dl})^{\mathrm{a}}$ & $12.5(1.7)$ & $13.4(2.0)$ & 0.0398 \\
\hline Albumin $(\mathrm{g} / \mathrm{dl})^{\mathrm{a}}$ & $4.1(0.4)$ & $4.3(0.6)$ & 0.0146 \\
\hline ASA score, n (\%) & & & 0.0252 \\
\hline 1,2 & $28(78)$ & $93(93)$ & \\
\hline 3 & $8(22)$ & $7(7)$ & \\
\hline Tumor size $(\mathrm{mm})^{\mathrm{a}}$ & $44.3(21.9)$ & $37.1(18.4)$ & 0.0593 \\
\hline Histological type, n (\%) & & & 0.2230 \\
\hline Differentiated & $16(44)$ & $32(32)$ & \\
\hline Undifferentiated & $20(56)$ & $68(68)$ & \\
\hline TNM classification $^{\mathrm{b}}$ & & & \\
\hline pT category, n (\%) & & & 0.1450 \\
\hline 1 & $22(61)$ & $72(72)$ & \\
\hline $2,3,4$ & $14(39)$ & $28(28)$ & \\
\hline $\mathrm{pN}$ category, $\mathrm{n}(\%)$ & & & 0.0755 \\
\hline 0 & $22(61)$ & $73(73)$ & \\
\hline $1,2,3$ & $14(39)$ & $27(27)$ & \\
\hline pStage, n (\%) & & & 0.1073 \\
\hline I & $21(58)$ & $77(77)$ & \\
\hline II & $7(19)$ & $13(13)$ & \\
\hline III & $8(22)$ & $10(10)$ & \\
\hline
\end{tabular}

LADG: Laparoscopy-assisted distal gastrectomy; BMI: body mass index; ASA: American Society of Anesthesiologists. Statistically significant values are shown in bold type. *Chi-squared or Fisher's exact test. aValues are shown as means (standard deviations). ${ }^{b}$ According to the Union for International Cancer Control (UICC) staging.

surgery during the hospital stay. Among the postoperative complications, anastomotic stenosis was more common in the elderly group ( $8 \% v s .1 \%, p=0.0567)$; however, this result was not statistically significant. The incidences of other complications were similar between the two groups (Table III).

The median follow-up periods of the elderly and nonelderly groups were 38 (10-50 months) and 39 (6-51 months), respectively. Of all 38 patients with stage II and III cancer, 25 received adjuvant chemotherapy (eight out of 15 in the elderly group; 17 out of 23 in the non-elderly group). The 3year overall survival (OS) rate was $87.9 \%$ in the elderly group and $95.9 \%$ in the non-elderly group $(p=0.1195)$ (Figure $1)$. No significant difference was observed in the 3-year recurrence-free survival (RFS) rate between the two groups ( $88.1 \%$ in the elderly group and $92.7 \%$ in the non-elderly group), whereas the 3-year disease-specific survival (DSS) rate was significantly lower in the elderly group (87.9\%) than in the non-elderly group (97.9\%) $(p=0.0277)$ (Figure 1). 
Table II. Intraoperative and postoperative data.

\begin{tabular}{|c|c|c|c|}
\hline & \multicolumn{2}{|c|}{ LADG $(\mathrm{n}=136)$} & \multirow[b]{2}{*}{$p$-Value* } \\
\hline & $\begin{array}{l}\text { Elderly } \\
(\mathrm{n}=36)\end{array}$ & $\begin{array}{l}\text { Non-elderly } \\
\quad(n=100)\end{array}$ & \\
\hline Mode of anastomosis, n (\%) & & & 0.0649 \\
\hline Billroth I & $23(64)$ & $81(81)$ & \\
\hline Billroth II & $0(0)$ & $0(0)$ & \\
\hline Roux-en-Y & $13(36)$ & $19(19)$ & \\
\hline Operative time $(\mathrm{min})^{\mathrm{a}}$ & $296.5(63.0)$ & $275.5(63.3)$ & 0.0900 \\
\hline Intraoperative & & & \\
\hline blood loss $(\mathrm{ml})^{\mathrm{a}}$ & $66.4(84.6)$ & $53.3(66.2)$ & 0.3471 \\
\hline $\begin{array}{l}\text { Lymph node } \\
\text { dissection } \mathrm{n}(\%)^{\mathrm{c}}\end{array}$ & & & 0.3964 \\
\hline $\mathrm{D} 1$ or $\mathrm{D} 1+$ & $24(67)$ & $74(74)$ & \\
\hline $\mathrm{D} 2$ & $12(33)$ & $26(26)$ & \\
\hline $\begin{array}{l}\text { Lymph nodes } \\
\text { resected, n }(\%)^{\mathrm{a}}\end{array}$ & $34.6(11.8)$ & $41.6(16.2)$ & 0.0190 \\
\hline $\begin{array}{l}\text { Time of first oral intake } \\
\text { after surgery (day) }\end{array}$ & 2 & 2 & 0.2139 \\
\hline $\begin{array}{l}\text { Postoperative hospital } \\
\text { stay }(\text { days) }\end{array}$ & 10 & 9 & 0.2077 \\
\hline
\end{tabular}

LADG: Laparoscopy-assisted distal gastrectomy. Statistically significant values are shown in bold type. *Chi-squared or Fisher's exact test. aValues are shown as means (standard deviations). bValues are shown as medians. ${ }^{\mathrm{c} A c c o r d i n g}$ to the treatment guidelines issued by the Japanese Cancer Association.

\section{Discussion}

LADG for early gastric cancer was first introduced in 1991 (16). During the past two decades, laparoscopic gastric cancer surgery has become increasingly common in Eastern Asia (17-19). Owing to shorter hospital stays and lower postoperative complication rates, laparoscopic surgery is widely performed for patients with gastric cancer, especially for those with early stage disease $(20,21)$. Many authors have reported its safety and effectiveness compared with open distal gastrectomy (9, 22-26). In large-scale phase III multicenter prospective randomized controlled trials for stage I gastric cancer (JCOG0912, KLASS01), it was confirmed that LADG was as safe as open distal gastrectomy in terms of adverse events and short-term clinical outcomes $(27,28)$. This suggested that laparoscopic gastrectomy was safe for elderly patients with early-stage gastric cancer.

Some previous reports have suggested that elderly patients with less functional reserve and more comorbid diseases may be harmed by carbon dioxide pneumoperitoneum, which is mostly harmless to non-elderly patients (29-31). However, Suzuki et al. showed that carbon dioxide pneumoperitoneum did not lead to severe morbidities in elderly patients (32). Consistent with the present study, they found no severe perioperative complications caused by carbon dioxide pneumoperitoneum in elderly patients who had significantly
Table III. Postoperative complications.

\begin{tabular}{lccc}
\hline & \multicolumn{2}{c}{ LADG (n=136), n (\%) } & \\
\cline { 2 - 3 } Complications $^{\mathrm{a}}$ & $\begin{array}{c}\text { Elderly } \\
(\mathrm{n}=36)\end{array}$ & $\begin{array}{c}\text { Non-elderly } \\
(\mathrm{n}=100)\end{array}$ & $p$-Value* \\
\hline Overall & $10(28)$ & $15(15)$ & 0.1301 \\
Clavien-Dindo grade $\geq \mathrm{III}$ & $4(11)$ & $5(5)$ & 0.2442 \\
Anastomotic leakage & $1(3)$ & $1(1)$ & 0.4608 \\
Anastomotic stenosis & $3(8)$ & $1(1)$ & 0.0567 \\
Intestinal obstruction & $0(0)$ & $1(1)$ & $>0.99$ \\
Chylous ascites & $0(0)$ & $2(2)$ & $>0.99$ \\
Clavien-Dindo grade 1 or 11 & $6(17)$ & $10(10)$ & 0.2842 \\
Paralytic Ileus & $0(0)$ & $3(3)$ & 0.5654 \\
Delayed gastric emptying & $1(3)$ & $4(4)$ & $>0.99$ \\
Chylous ascites & $1(3)$ & $0(0)$ & 0.2647 \\
Wound infection & $1(3)$ & $0(0)$ & 0.2647 \\
Pneumonia & $1(3)$ & $2(2)$ & $>0.99$ \\
Delirium & $1(3)$ & $1(1)$ & 0.4608 \\
Liver dysfunction & $1(3)$ & $0(0)$ & 0.2647 \\
\hline
\end{tabular}

LADG: Laparoscopy-assisted distal gastrectomy. ${ }^{*}$ Chi-squared or Fisher's exact test. aAccording to a modification of the Clavien-Dindo grading system.

higher ASA scores. Several studies have also reported that laparoscopic gastrectomy is safe for elderly as well as for non-elderly patients in short-term surgical outcome $(10,11$, 33-35). In addition, we found no significant differences in intraoperative blood loss, operative time and complications after surgery between the elderly and non-elderly groups.

Moreover, LADG for gastric cancer in elderly patients may be superior to conventional open resection in regard to some surgical outcomes $(36,37)$. Zong et al. performed a meta-analysis that compared laparoscopic and open gastrectomy for elderly patients with gastric cancer. They showed that laparoscopic gastrectomy significantly reduced both surgery-related and systemic morbidities compared with open gastrectomy and did not increase cardiopulmonary or mental dysfunctions (7). However, in order to show whether laparoscopic gastrectomy is technically feasible and advantageous for elderly patients, a multi-center randomized controlled trial with greatly increased sample sizes is needed in the future.

Regarding the prognosis, there was no significant difference in the 3-year OS nor RFS between the elderly and non-elderly groups in this study. Although age distribution and follow-up period were different, Yoshida et al. reported that 3-year OS was significantly lower in their elderly group than in their non-elderly group, but RFS was not different, as in our study. In their study, 3-year OS was 74.2\% in the elderly group (aged $\geq 80$ years, 31 patients), and only one elderly patient died from a recurrence of gastric cancer, whereas more patients died of other diseases. In the present study, only one patient died due 

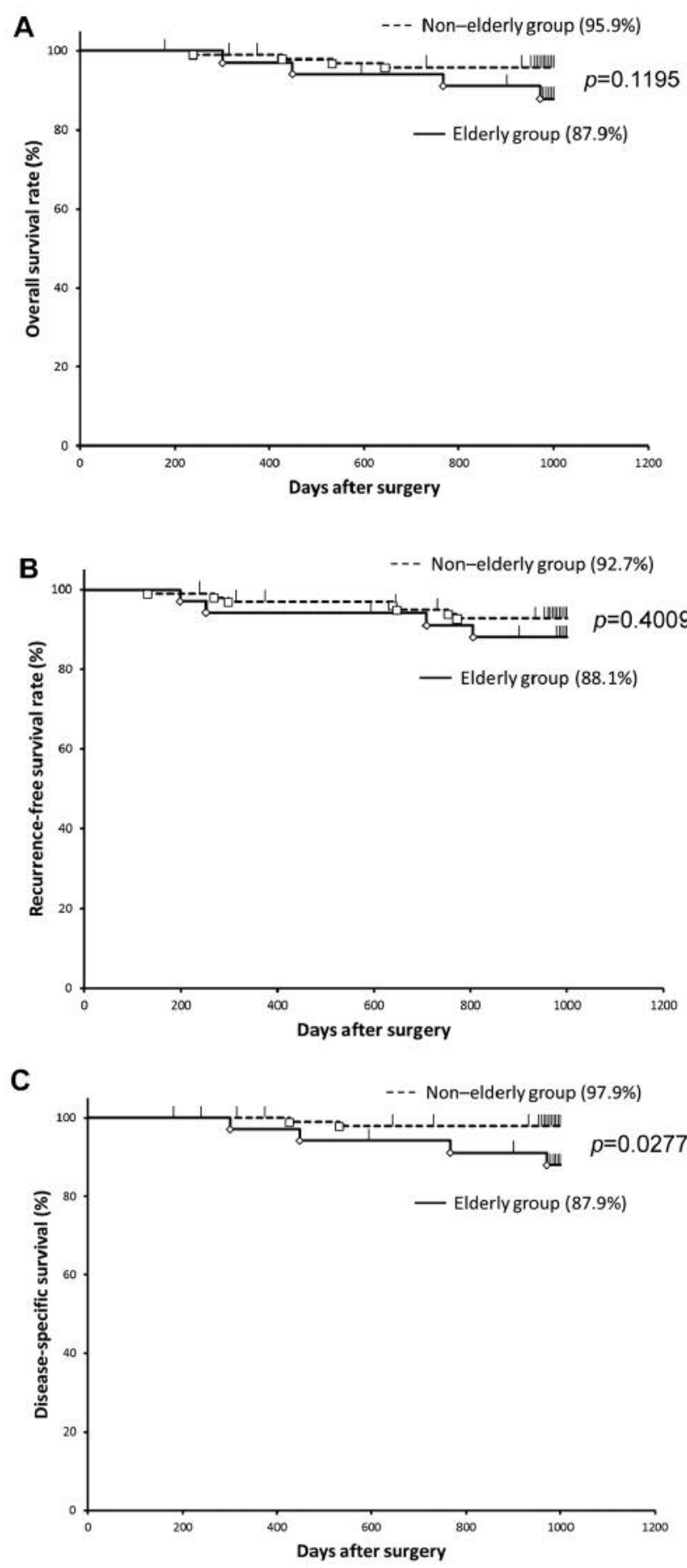

Figure 1. Postoperative overall $(A)$, recurrence-free $(B)$ and diseasespecific $(C)$ survival curves for the elderly and non-elderly groups. A: The 3-year overall survival was $87.9 \%$ in the elderly group and $95.9 \%$ in the non-elderly group ( $p=0.1195)$. B: No significant difference was observed in 3-year recurrence-free survival between the two groups (88.1\% in the elderly group and $92.7 \%$ in the non-elderly group) ( $p=0.4009)$. C: The 3-year disease-specific survival was significantly lower in the elderly group (87.9\%) than in the non-elderly group (97.9\%) $(p=0.0277)$. to other diseases in the elderly group. Thus, our study indicates that the low invasion of laparoscopic surgery could be one of the means to prevent death from other diseases after surgery. However, DSS was significantly lower in the elderly group than in the non-elderly group in this study. One of the reasons for this might be that elderly patients have poor tolerability to chemotherapy. The number of elderly patients with stage II and III cancer who were able to receive adjuvant chemotherapy was smaller than that of non-elderly patients, and there was only one elderly patient who was able to receive chemotherapy after recurrence in this study. An appropriate strategy for chemotherapy for elderly patients with gastric cancer is an urgent issue.

In conclusion, the results of our study demonstrated that LADG can be safely performed for both elderly and nonelderly patients with gastric cancer. Furthermore, elderly patients whose cancer did not recur after LADG had a good prognosis similar to that of non-elderly patients.

\section{Conflicts of Interest}

The Authors have no conflict of interest to declare in association with this study.

\section{References}

1 Ferlay J, Soerjomataram I, Dikshit R, Eser S, Mathers C, Rebelo M, Parkin DM, Forman D and Bray F: Cancer incidence and mortality worldwide: Sources, methods and major patterns in globocan 2012. Int J Cancer 136(5): E359-386, 2015.

2 Lichtman SM, Hurria A and Jacobsen PB: Geriatric oncology: An overview. J Clin Oncol 32(24): 2521-2522, 2014.

3 Cho GS, Kim W, Kim HH, Ryu SW, Kim MC and Ryu SY: Multicentre study of the safety of laparoscopic subtotal gastrectomy for gastric cancer in the elderly. Br J Surg 96(12): 1437-1442, 2009.

4 Endo S, Dousei T, Yoshikawa Y, Hatanaka N, Kamiike W and Nishijima J: Prognosis of gastric carcinoma patients aged 85 years or older who underwent surgery or who received best supportive care only. Int J Clin Oncol 18(6): 1014-1019, 2013.

5 Kim EJ, Seo KW and Yoon KY: Laparoscopy-assisted distal gastrectomy for early gastric cancer in the elderly. J Gastric Cancer 12(4): 232-236, 2012.

6 Yamada H, Kojima K, Inokuchi M, Kawano T and Sugihara K: Laparoscopy-assisted gastrectomy in patients older than 80 . J Surg Res 161(2): 259-263, 2010.

7 Zong L, Wu A, Wang W, Deng J, Aikou S, Yamashita H, Maeda M, Abe M, Yu D, Jiang Z, Seto Y and Ji J: Feasibility of laparoscopic gastrectomy for elderly gastric cancer patients: Meta-analysis of non-randomized controlled studies. Oncotarget 8(31): 51878-51887, 2017.

8 Kunisaki C, Makino H, Takagawa R, Oshima T, Nagano Y, Ono $\mathrm{HA}$, Akiyama $\mathrm{H}$ and Shimada H: Efficacy of laparoscopyassisted distal gastrectomy for gastric cancer in the elderly. Surg Endosc 23(2): 377-383, 2009.

9 Kim MG, Kim HS, Kim BS and Kwon SJ: The impact of old age on surgical outcomes of totally laparoscopic gastrectomy for gastric cancer. Surg Endosc 27(11): 3990-3997, 2013. 
10 Yoshida M, Koga S, Ishimaru K, Yamamoto Y, Matsuno Y, Akita S, Kuwabara J, Tanigawa K and Watanabe Y: Laparoscopyassisted distal gastrectomy is feasible also for elderly patients aged 80 years and over: Effectiveness and long-term prognosis Surg Endosc 31(11): 4431-4437, 2017.

11 Fujisaki M, Shinohara T, Hanyu N, Kawano S, Tanaka Y, Watanabe A and Yanaga K: Laparoscopic gastrectomy for gastric cancer in the elderly patients. Surg Endosc 30(4): 1380-1387, 2016.

12 Japanese Gastric Cancer A: Japanese classification of gastric carcinoma: 3rd english edition. Gastric Cancer 14(2): 101-112, 2011.

13 Saklad M: Grading of patients for surgical procedures. Anesthesiology 2(3): 281-284, 1941.

14 Japanese Gastric Cancer A: Japanese gastric cancer treatment guidelines 2014 (ver. 4). Gastric Cancer 20(1): 1-19, 2017.

15 Sakuramoto S, Kikuchi S, Kuroyama S, Futawatari N, Katada N, Kobayashi $\mathrm{N}$ and Watanabe M: Laparoscopy-assisted distal gastrectomy for early gastric cancer: Experience with 111 consecutive patients. Surg Endosc 20(1): 55-60, 2006.

16 Kitano S, Iso Y, Moriyama M and Sugimachi K: Laparoscopyassisted billroth i gastrectomy. Surg Laparosc Endosc 4(2): 146148, 1994.

17 Yang HK, Suh YS and Lee HJ: Minimally invasive approaches for gastric cancer-korean experience. J Surg Oncol 107(3): $277-$ $281,2013$.

18 Etoh $\mathrm{T}$, Inomata $\mathrm{M}$, Shiraishi $\mathrm{N}$ and Kitano S: Minimally invasive approaches for gastric cancer-japanese experiences. J Surg Oncol 107(3): 282-288, 2013.

19 Chen XZ, Li YY, Hu JK, Yang K, Liu J, Zhang B, Chen ZX, Chen JP and Zhou ZG: Spread and development of laparoscopic surgery for gastric tumors in mainland china: Initial experiences. Hepatogastroenterology 59(114): 654-658, 2012.

20 Zeng YK, Yang ZL, Peng JS, Lin HS and Cai L: Laparoscopyassisted versus open distal gastrectomy for early gastric cancer: Evidence from randomized and nonrandomized clinical trials. Ann Surg 256(1): 39-52, 2012.

21 Chen XZ, Hu JK, Yang K, Wang L and Lu QC: Short-term evaluation of laparoscopy-assisted distal gastrectomy for predictive early gastric cancer: A meta-analysis of randomized controlled trials. Surg Laparosc Endosc Percutan Tech 19(4): 277-284, 2009.

22 Kitano S, Shiraishi N, Uyama I, Sugihara K, Tanigawa N and Japanese Laparoscopic Surgery Study G: A multicenter study on oncologic outcome of laparoscopic gastrectomy for early cancer in japan. Ann Surg 245(1): 68-72, 2007.

23 Lee JH, Park DJ, Kim HH, Lee HJ and Yang HK: Comparison of complications after laparoscopy-assisted distal gastrectomy and open distal gastrectomy for gastric cancer using the claviendindo classification. Surg Endosc 26(5): 1287-1295, 2012.

24 Memon MA, Khan S, Yunus RM, Barr R and Memon B: Metaanalysis of laparoscopic and open distal gastrectomy for gastric carcinoma. Surg Endosc 22(8): 1781-1789, 2008.

25 Kitano S, Shiraishi N, Fujii K, Yasuda K, Inomata M and Adachi $\mathrm{Y}$ : A randomized controlled trial comparing open vs. laparoscopyassisted distal gastrectomy for the treatment of early gastric cancer: An interim report. Surgery 131(1 Suppl): S306-311, 2002.

26 Kim YW, Yoon HM, Yun YH, Nam BH, Eom BW, Baik YH, Lee SE, Lee Y, Kim YA, Park JY and Ryu KW: Long-term outcomes of laparoscopy-assisted distal gastrectomy for early gastric cancer: Result of a randomized controlled trial (coact 0301). Surg Endosc 27(11): 4267-4276, 2013.
27 Katai H, Mizusawa J, Katayama H, Takagi M, Yoshikawa T, Fukagawa T, Terashima M, Misawa K, Teshima S, Koeda K, Nunobe S, Fukushima N, Yasuda T, Asao Y, Fujiwara Y and Sasako M: Short-term surgical outcomes from a phase iii study of laparoscopy-assisted versus open distal gastrectomy with nodal dissection for clinical stage ia/ib gastric cancer: Japan clinical oncology group study jcog0912. Gastric Cancer 20(4): 699-708, 2017.

28 Kim W, Kim HH, Han SU, Kim MC, Hyung WJ, Ryu SW, Cho GS, Kim CY, Yang HK, Park DJ, Song KY, Lee SI, Ryu SY, Lee $\mathrm{JH}$, Lee HJ and Korean Laparo-endoscopic Gastrointestinal Surgery Study G: Decreased morbidity of laparoscopic distal gastrectomy compared with open distal gastrectomy for stage i gastric cancer: Short-term outcomes from a multicenter randomized controlled trial (klass-01). Ann Surg 263(1): 28-35, 2016.

29 Ballesta Lopez C, Cid JA, Poves I, Bettonica C, Villegas L and Memon MA: Laparoscopic surgery in the elderly patient. Surg Endosc 17(2): 333-337, 2003.

30 Mayol J, Martinez-Sarmiento J, Tamayo FJ and FernandezRepresa JA: Complications of laparoscopic cholecystectomy in the ageing patient. Age Ageing 26(2): 77-81, 1997.

31 Turrentine FE, Wang H, Simpson VB and Jones RS: Surgical risk factors, morbidity, and mortality in elderly patients. J Am Coll Surg 203(6): 865-877, 2006.

32 Suzuki S, Nakamura T, Imanishi T, Kanaji S, Yamamoto M, Kanemitsu K, Yamashita K, Sumi Y, Tanaka K, Kuroda D and Kakeji Y: Carbon dioxide pneumoperitoneum led to no severe morbidities for the elderly during laparoscopic-assisted distal gastrectomy. Ann Surg Oncol 22(5): 1548-1554, 2015.

33 Anegawa G, Nakashima Y, Fujinaka Y and Takahashi I: Laparoscopy-assisted distal gastrectomy for early gastric cancer poses few limitations for selected elderly patients: A single-center experience. Surg Case Rep 2(1): 56, 2016.

34 Kouzu K, Tsujimoto H, Hiraki S, Horiguchi H, Nomura S, Ito N, Kanematsu K, Yamazaki K, Aosasa S, Yamamoto J and Hase K: Efficacy of totally laparoscopic distal gastrectomy for gastric cancer in elderly patients. Mol Clin Oncol 4(6): 976-982, 2016.

35 Wang JF, Zhang SZ, Zhang NY, Wu ZY, Feng JY, Ying LP and Zhang JJ: Laparoscopic gastrectomy versus open gastrectomy for elderly patients with gastric cancer: A systematic review and meta-analysis. World J Surg Oncol 14: 90, 2016.

36 Zheng L, Lu L, Jiang X, Jian W, Liu Z and Zhou D: Laparoscopy-assisted versus open distal gastrectomy for gastric cancer in elderly patients: A retrospective comparative study. Surg Endosc 30(9): 4069-4077, 2016.

37 Li H, Han X, Su L, Zhu W, Xu W, Li K, Zhao Q, Yang H and Liu H: Laparoscopic radical gastrectomy versus traditional open surgery in elderly patients with gastric cancer: Benefits and complications. Mol Clin Oncol 2(4): 530-534, 2014.

Received December 24, 2017

Revised January 24, 2018

Accepted January 29, 2018 